\title{
Granulocyte colony-stimulating factor therapy for stem cell mobilization following anterior wall myocardial infarction: the CAPITAL STEM MI randomized trial
}

\author{
Benjamin Hibbert MD PhD, Bradley Hayley MD, Robert S. Beanlands MD, Michel Le May MD, \\ Richard Davies MD, Derek So MD, Jean-François Marquis MD, Marino Labinaz MD, Michael Froeschl MD, \\ Edward R. O'Brien MD, lan G. Burwash MD, George A. Wells PhD, Ali Pourdjabbar MD, Trevor Simard MD, \\ Harold Atkins MD, Christopher Glover MD
}

\section{ABSTRACT \\ Background: Small studies have yielded diver- gent results for administration of granulocyte colony-stimulating factor (G-CSF) after acute myocardial infarction. Adequately powered studies involving patients with at least moder- ate left ventricular dysfunction are lacking.}

Methods: Patients with left ventricular ejection fraction less than $45 \%$ after anterior-wall myocardial infarction were treated with G-CSF $(10 \mu \mathrm{g} / \mathrm{kg}$ daily for 4 days) or placebo. After initial randomization of 86 patients, 41 in the placebo group and 39 in the G-CSF group completed 6-month follow-up and underwent measurement of left ventricular ejection fraction by radionuclide angiography.

Results: Baseline and 6-week mean ejection fraction was similar for the G-CSF and placebo groups: $34.8 \%$ (95\% confidence interval [Cl] $32.6 \%-37.0 \%)$ v. $36.4 \%(95 \% \mathrm{Cl} 33.5 \%-39.2 \%)$ at baseline and $39.8 \%(95 \% \mathrm{Cl} 36.2 \%-43.4 \%)$ v. $43.1 \%(95 \% \mathrm{Cl} 39.2 \%-47.0 \%)$ at 6 weeks.
However, G-CSF therapy was associated with a lower ejection fraction at 6 months relative to placebo $(40.8 \%$ [ $95 \%$ Cl $37.4 \%-44.2 \%$ ] v. $46.0 \%$ [95\% Cl 42.7\%-44.3\%]). Both groups had improved left ventricular function, but change in left ventricular ejection fraction was lower in patients treated with G-CSF than in those who received placebo $(5.7$ [95\% Cl 3.4-8.1] percentage points v. $9.2[95 \% \mathrm{Cl} 6.3-12.1]$ percentage points). One or more of a composite of several major adverse cardiac events occurred in 8 patients (19\%) within each group, with similar rates of target-vessel revascularization.

Interpretation: In patients with moderate left ventricular dysfunction following anterior-wall infarction, G-CSF therapy was associated with a lower 6-month left ventricular ejection fraction but no increased risk of major adverse cardiac events. Future studies of G-CSF in patients with left ventricular dysfunction should be monitored closely for safety. Trial registration: ClinicalTrials.gov, no. NCT00394498
Competing interests: Derek So has received grants from Spartan Bioscience Inc. and Abbott Vascular Canada for physician-initiated research outside the scope of the work reported here, as well as honoria from Lilly

Canada for lectures. No other competing interests were declared.

Disclaimer: George Wells is a member of $C M A J$ 's Editorial Board and was not involved in the editorial decision-making process for this article.

This article has been peer reviewed.

Correspondence to: Christopher Glover, cglover@ottawaheart.ca

CMAJ 2014. DOI:10.1503 /cmaj.140133
$\mathrm{R}$ apid reperfusion therapy has become the standard treatment for ST-segment elevation myocardial infarction (STEMI), with congestive heart failure and left ventricular dysfunction continuing as the strongest predictors of higher long-term risk. ${ }^{1}$ To date, no definitive therapies exist to regenerate myocardium following myocardial necrosis, and myocardial preservation is therefore the goal of STEMI care. Contemporary studies have suggested the possibility of myocardial regeneration by endogenous stem and progenitor cell populations, and preliminary clinical studies have hinted at potential benefit. ${ }^{2,3}$ Studies investigating whether postinfarction myocardial function can be improved by enhancing stem cell-mediated repair are in progress (NCT00936819 and NCT00984178).

Granulocyte colony-stimulating factor (G-
CSF), an endogenously produced glycoprotein growth factor, when given in pharmacologic doses, stimulates mobilization of hematopoietic stem cells into the peripheral blood. Therapeutically, recombinant synthetic forms have been used to enhance recovery from neutropenia following chemotherapy and for mobilization of stem cells before hematopoietic stem cell transplant. ${ }^{4}$ Numerous small clinical studies have investigated the potential of G-CSF-induced mobilization of stem cells in the peri-infarction period to enhance left ventricular recovery, but they have yielded discordant results. However, meta-analyses have suggested benefit for left ventricular ejection fraction in subgroups who received G-CSF early after infarction or in patients whose left ventricular dysfunction was mild to moderate. ${ }^{5,6}$ Larger trials are necessary because, in addition to mobilizing stem 
cells, G-CSF modulates intracellular signalling cascades within cardiomyocytes and can activate neutrophils, and several trials have been stopped early as a result of excessive in-stent restenosis and acute coronary syndromes in patients with coronary artery disease. ${ }^{7-11}$ Animal data have similarly yielded discordant results, depending on the dose and timing of G-CSF. ${ }^{12}$

To clarify the role of G-CSF in promoting left ventricular recovery after acute myocardial infarction, we performed an adequately powered randomized clinical trial in patients with moderate left ventricular dysfunction following anteriorwall STEMI.

\section{Methods}

\section{Study design and patients}

The University of Ottawa Heart Institute regional STEMI program services a population of about 1.3 million residents in eastern Ontario. ${ }^{13,14}$ The CArdiovascular Percutaneous Intervention TriAL group's G-CSF for STEM cell mobilization post Myocardial Infarction (CAPITAL STEM MI, NCT00394498) trial was a prospective, randomized clinical study involving consecutive eligible patients referred for care between October 2005 and March 2010. Inclusion criteria specified presentation with anterior-wall STEMI with ejection fraction less than $45 \%$. Reperfusion could be achieved by primary percutaneous coronary intervention (PCI) or thrombolysis followed by rescue or pharmacoinvasive PCI with insertion of 1 or more coronary stents. Exclusion criteria were prior STEMI, regional-wall motion abnormalities in non-infarct-related regions, prior coronary artery bypass grafting, severe valve disease (i.e., more than moderate), active infection requiring intravenous antibiotics, confirmed or possible pregnancy, enrolment in another clinical trial and left ventricular dysfunction with known or suspected nonischemic cause.

The study was double-blinded and placebocontrolled. Randomization was achieved by a computer-generated randomization sequence, with patient assignment determined by opening sealed opaque envelopes. Enrolment and randomization were performed by study staff, and blinding of patients and physicians was maintained by preparation of placebo in syringes packaged similarly to those containing G-CSF. The intervention consisted of G-CSF (Filgrastim, Amgen, Mississauga, Ont.) administered subcutaneously at a dose of $10 \mu \mathrm{g} / \mathrm{kg}$ daily for 4 days beginning on day 3 or 4 after STEMI. Adjuvant pharmacotherapy was administered at the discretion of the treating physician.

The study was approved by the University of Ottawa Heart Institute Human Research Ethics
Board, and all patients provided written informed consent.

\section{Outcome measures}

We performed clinical follow-up at 6 weeks and 6 months. The primary outcome was left ventricular ejection fraction, as assessed by left ventricular radionuclide angiography at 6 months. Secondary end points were left ventricular ejection fraction at 6 weeks, change in ejection fraction over time and a composite of major adverse cardiac events at 6 months, including death, cerebrovascular accident (as diagnosed by a treating neurologist), targetvessel revascularization and severe heart failure requiring admission.

Left ventricular radionuclide angiography Electrocardiogram-gated equilibrium blood pool images were obtained in $45^{\circ}$ left anterior oblique views with a Cardial-Apex camera (GE). We calculated the left ventricular ejection fraction using the mean of 2 measurements for the enddiastolic and end-systolic counts. All measurements were performed by a single technologist, and images were processed using a standard software package (Xpert Workstation). Both the technologist and the reading physician (R.S.B.) remained blinded to the treatment assignment. More detailed protocols for blood counts and left ventricular diastolic function are available in Appendix 1 (available at www.cmaj.ca/lookup /suppl/doi:10.1503/cmaj.140133/-/DC1).

\section{Statistical analysis}

Continuous variables are reported as means ( \pm standard deviations) or medians (and interquartile ranges [IQRs]), as appropriate, and categorical variables as numbers (percentages). Continuous variables were compared by Student $t$ test or Mann-Whitney rank sum test and categorical variables by Fisher exact test or $\chi^{2}$ test, as appropriate. For comparison of final left ventricular ejection fraction and change in left ventricular ejection fraction, we used a mixedmodel repeated-measures analysis, with treatment group as the "between" factor (G-CSF v. placebo) and time as the "within" factor (baseline, $6 \mathrm{wk}, 6 \mathrm{mo}$ ). To calculate sample size, we estimated that the left ventricular ejection fraction in the G-CSF group would be $4 \%$ higher than in the placebo group, on the basis of previous studies and consensus among the investigators regarding a minimal clinically important difference. Using an estimated standard deviation of $6 \%$ and a level of significance $(\alpha)$ of 0.05 , we calculated a necessary sample size of 38 patients per group to have $80 \%$ power to detect a significant difference. We assumed that 
5 patients would not complete the study because of death or drop-out, and therefore recruited 43 patients per group.

All analyses were performed using SAS software version 9.2 and Mix Meta-analysis version 1.7. Differences with a $p$ value of 0.05 or less were considered significant. All imaging data were interpreted with blinding, and none of the interpreting physicians were aware of the treatment group.

\section{Meta-analysis}

We updated previous meta-analyses ${ }^{5,6}$ to include the results of the current study. The complete methods, described in detail previously, ${ }^{15}$ can be reviewed in Appendix 1 (available at www.cmaj.ca /lookup/suppl/doi:10.1503/cmaj.140133/-/DC1).

\section{Results}

\section{Population and baseline characteristics}

Eighty-six consecutive eligible patients were enrolled in the study (Figure 1). A single patient in each group withdrew consent following randomization, and all data for these 2 patients were withdrawn from the analysis. Furthermore, before the 6-month follow-up, a single patient in each group died, and in the G-CSF group 1 patient was lost to follow-up and 1 patient underwent cardiac transplant. Accordingly, 41 patients in the placebo group and 39 patients in the G-CSF group completed 6-month followup and were included in the primary outcome analysis. As expected, baseline demographic characteristics, procedure-related variables and medical therapy were similar between the groups (Table 1).

\section{Effect of G-CSF on laboratory results and stem cell mobilization}

Baseline hematologic values, specifically leukocyte counts, hemoglobin, platelet counts and components of the leukocyte count (lymphocytes, monocytes and neutrophils), were all similar between the 2 groups (Table 2). By day 4, treatment with G-CSF was associated with higher leukocyte counts $\left(49.8 \pm 12.8 \times 10^{9} / \mathrm{L}\right.$ v. $\left.9.2 \pm 2.7 \times 10^{9} / \mathrm{L}, p<0.001\right)$, and more $\mathrm{CD} 34^{+}$ cells were effectively mobilized into the circulation (median 52.5 [IQR 25.0-84.0] cells/ $\mu \mathrm{L}$ v. 5.0

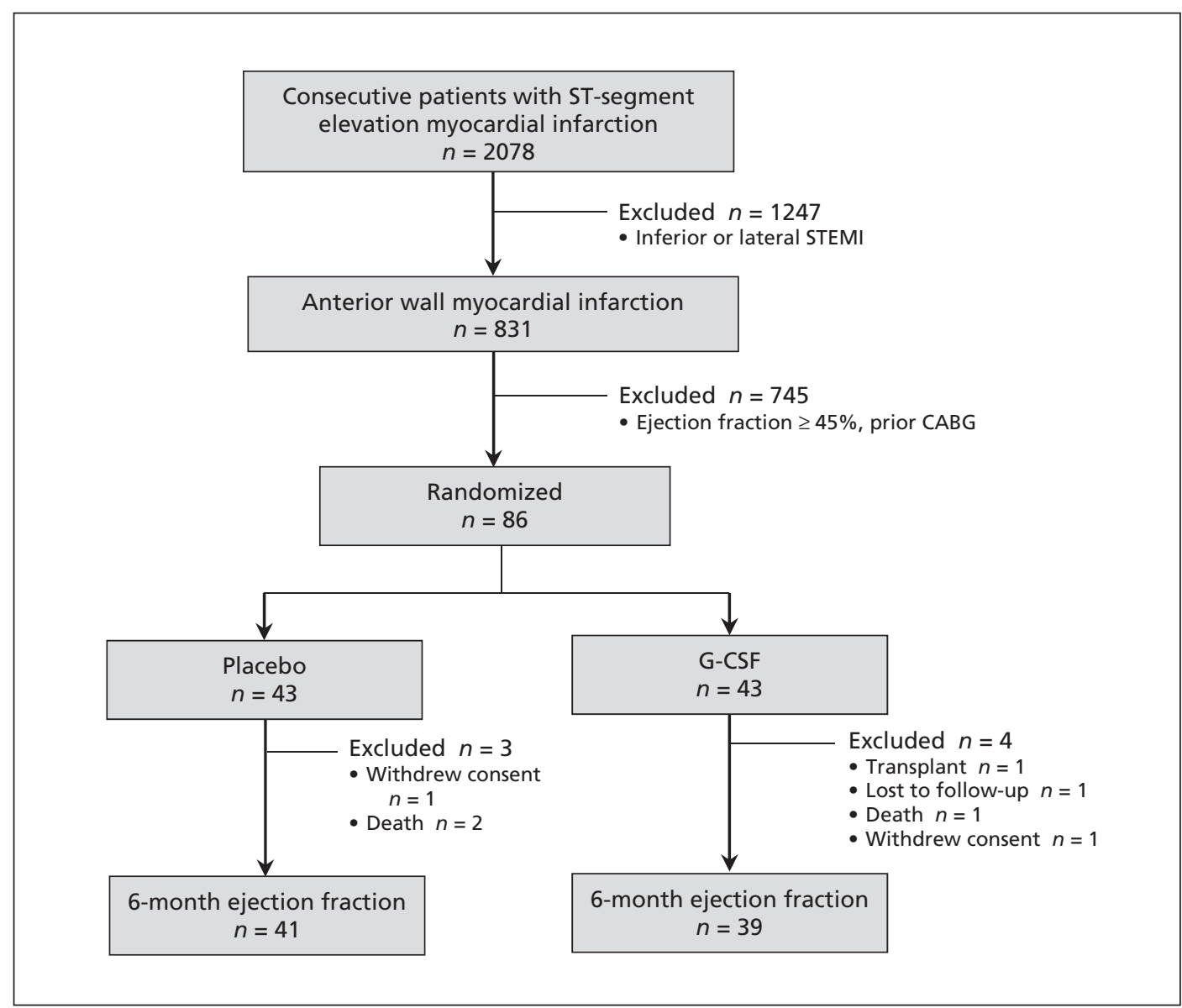

Figure 1: Flow diagram for randomized controlled trial of patients who experienced ST-segment elevation myocardial infarction between October 2005 and March 2010 and who received either granulocyte colonystimulating factor (G-CSF) or placebo. 
Table 1: Baseline and myocardial infarction-related characteristics

\begin{tabular}{|c|c|c|}
\hline \multirow[b]{2}{*}{ Characteristic } & \multicolumn{2}{|c|}{ Group; no. (\%) of patients* } \\
\hline & $\begin{array}{c}\text { Placebo } \\
n=42\end{array}$ & $\begin{array}{l}\text { G-CSF } \\
n=42\end{array}$ \\
\hline Age, yr, mean \pm SD & $57.0 \pm 9.2$ & $53.3 \pm 8.7$ \\
\hline Sex, male & $34 \quad(81)$ & $35 \quad(83)$ \\
\hline \multicolumn{3}{|l|}{ Concurrent conditions } \\
\hline Hypertension & $16 \quad(38)$ & $14 \quad(33)$ \\
\hline Diabetes mellitus & $6 \quad(14)$ & $12 \quad(29)$ \\
\hline Dyslipidemia & $7 \quad(17)$ & $10 \quad(24)$ \\
\hline Smoking & $22 \quad(52)$ & $14 \quad(33)$ \\
\hline \multicolumn{3}{|l|}{ Cardiovascular history } \\
\hline Myocardial infarction & $6 \quad(14)$ & $5 \quad(12)$ \\
\hline $\mathrm{PCl}$ & $4 \quad(10)$ & (0) \\
\hline Stroke & $0 \quad(0)$ & $1 \quad(2)$ \\
\hline \multicolumn{3}{|l|}{ Killip class } \\
\hline I or II & $40 \quad(95)$ & $40 \quad(95)$ \\
\hline III or IV & $2 \quad(5)$ & (7) \\
\hline Creatinine, $\mu \mathrm{mol} / \mathrm{L}$, mean $\pm \mathrm{SD}$ & $89.6 \pm 21.7$ & $90.5 \pm 25.7$ \\
\hline Peak creatinine kinase, units/L, & 2932 (1890-4769) & $3180(1610-4701)$ \\
\hline
\end{tabular}

median (IQR)

Revascularization

\begin{tabular}{|c|c|c|}
\hline Pharmacoinvasive & $8 \quad(19)$ & 12 (29) \\
\hline Primary $\mathrm{PCl}$ & $34 \quad(81)$ & $31 \quad(74)$ \\
\hline $\begin{array}{l}\text { Symptom onset to presentation, } \\
\text { min, median (IQR) }\end{array}$ & $360(60-1440)$ & $150(60-735)$ \\
\hline Presentation to reperfusion & $60(55-90)$ & $60(60-90)$ \\
\hline
\end{tabular}

therapy, min, median (IQR)

TIMI flow before $\mathrm{PCI}$

$\begin{array}{rrrrr}0 & 27 & (64) & 23 & (55) \\ 1 & 3 & (7) & 5 & (12) \\ 2 & 4 & (10) & 7 & (17) \\ 3 & 8 & (19) & 8 & (19)\end{array}$

TIMI flow after $\mathrm{PCI}$

$\begin{array}{rrrrr}0 & 2 & (5) & 0 & (0) \\ 1 & 0 & (0) & 0 & (0) \\ 2 & 1 & (2) & 2 & (5) \\ 3 & 39 & (93) & 41 & (98)\end{array}$

Discharge medications

$\begin{array}{lll}\text { Acetylsalicylic acid } & 42(100) & 42(100) \\ \text { Clopidogrel } & 42(100) & 42(100) \\ \text { Warfarin } & 14(33) & 21(50) \\ \beta \text {-Blocker } & 42(100) & 42(100) \\ \text { ACE inhibitor/ARB } & 41(98) & 41(98) \\ \text { Statin } & 42(100) & 42(100)\end{array}$

Note: $\mathrm{ACE}=$ angiotensin-converting enzyme, $\mathrm{ARB}=$ angiotensin receptor blocker, $\mathrm{G}-\mathrm{CSF}=$ granulocyte colony-stimulating factor, $\mathrm{IQR}=$ interquartile range, $\mathrm{PCl}=$ percutaneous coronary intervention, $\mathrm{SD}=$ standard deviation, $\mathrm{TIMI}=$ thrombolysis in myocardial infarction.

*Unless otherwise stated.
[IQR 3.2-6.0] cells/ $\mu \mathrm{L}, p<0.001$ ), relative to placebo. No differences existed between the groups at 6 and 26 weeks of follow-up.

\section{Primary and secondary outcomes}

The primary outcome, absolute left ventricular ejection fraction as assessed by radionuclide angiography, was significantly lower in the GCSF treatment group than in the placebo group: $40.8 \%$ (95\% confidence interval [CI] $37.4 \%$ to $44.2 \%$ ) v. $46.0 \%$ (95\% CI $42.7 \%$ to $44.3 \%$ ) (Table 3). Notably, no significant differences in left ventricular ejection fraction were observed between the G-CSF and placebo groups at baseline. Moreover, change in ejection fraction - a prespecified secondary end point - did not differ significantly between the 2 groups, although less recovery was observed in patients treated with GCSF than in those treated with placebo (5.7 [95\% CI 3.4 to 8.1] percentage points v. 9.2 [95\% CI 6.3 to 12.1] percentage points). Nonetheless, both groups showed left ventricular recovery in the postinfarction period. The effect of G-CSF on diastolic function is presented in Table 4 .

The secondary end point of a major adverse cardiac event by 6 months occurred in 8 patients (19\%) in each group (Table 3). Specifically, 1 death and 1 case requiring coronary artery bypass graft occurred in each group. Notably, rates of target-vessel revascularization were similar between the placebo and G-CSF groups (14\% v. $12 \%)$. One patient in the G-CSF group underwent cardiac transplant at 4 months after infarction, with a 6-week ejection fraction of $14 \%$.

\section{Interpretation}

This trial was designed to ensure adequate power in investigating the use of G-CSF in patients with moderate left ventricular dysfunction following anterior-wall myocardial infarction. Contrary to the primary hypothesis, G-CSF therapy resulted in lower left ventricular ejection fraction (by 5.7 percentage points) at 6-month follow-up. Furthermore, our updated meta-analysis involving 14 randomized studies suggested no benefit of G-CSF following acute myocardial infarction but provided no signal of increased major adverse cardiac events in patients receiving this therapy. Nonetheless, the significant negative effect of G-CSF on left ventricular ejection fraction observed in the current study raises concerns about the safety of this therapy for patients with moderate left ventricular dysfunction following myocardial infarction. Although no definite increase in major adverse cardiac events was observed, the current study and the associated meta-analysis remain underpowered, and followup to date has been inadequate to detect impor- 
tant differences in clinical outcomes that may result from lower left ventricular ejection fraction over the long term. As a result, ongoing studies with G-CSF for left ventricular recovery warrant careful long-term monitoring of ejection fraction and clinical outcomes to ensure safety.

In addition to mobilization of progenitor cells, G-CSF has been shown to have pleiotropic effects following myocardial infarction. For example, reduction in myocyte apoptosis ${ }^{16}$ and reductions in arrhythmias through upregulation of connexin 43 have been reported. ${ }^{17}$ Thus, whereas mobilization of progenitor cells is one manner in which G-CSF may alter the myocardial healing process, pleiotropic effects may alter the expected response to therapy. In the current study, mobilization of progenitor cells did not correlate with left ventricular recovery, and the mechanisms by which G-CSF may have impaired systolic function remain unclear. However, G-CSF has been reported to have pro-inflammatory and thrombotic effects, both of which may contribute to impairment of left ventricular recovery. ${ }^{18}$ Nonetheless, our results highlight the difficulty of translating findings from preclinical animal models into therapeutic practice and emphasize the need for welldesigned clinical trials.

A previous meta-analysis suggested that patients with left ventricular ejection fraction less than $50 \%$ benefited from administration of G-CSF after myocardial infarction. ${ }^{5}$ Given the results of our study, we updated the meta-analysis to include 14 randomized trials with a total of 566 patients (see Appendix 2, available at www .cmaj.ca/lookup/suppl/doi:10.1503/cmaj.140133 /-/DC1). Our updated analysis showed no effect of G-CSF on left ventricular ejection fraction (Appendix 2, Figure 2A, mean difference 2.0 [ $95 \% \mathrm{CI}-0.9$ to 4.8$]$ percentage points, $p=0.2$ ). In a prespecified secondary analysis, including only studies with baseline left ventricular ejection fraction less than $45 \%$, there was no benefit of GCSF for this subset of patients when the findings of the current study were factored in (Appendix 2, Figure 2B, mean difference 0.7 [95\% CI -2.5 to 4.0 ] percentage points, $p=0.7$ ). Overall, in the 12 studies reporting major adverse cardiac events, no difference was observed between G-CSF and

Table 2: Laboratory test results for patients who received placebo or G-CSF after myocardial infarction

\begin{tabular}{|c|c|c|c|c|c|}
\hline \multirow[b]{2}{*}{ Variable } & \multicolumn{5}{|c|}{ Time after treatment; data value, mean $\pm \mathrm{SD}$ * } \\
\hline & Day 0 & Day 4 & $1 \mathrm{wk}$ & 6 wk & 26 wk \\
\hline \multicolumn{6}{|l|}{ 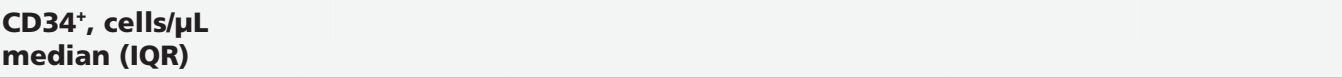 } \\
\hline Placebo group & $3.0(2.0-6.0)$ & $5.0(3.2-6.0)$ & $2.0(1.5-5.0)$ & NA & NA \\
\hline G-CSF group & $4.0(2.0-7.0)$ & $52.5(25.0-84.0) \dagger$ & $3.0(2.0-5.0)$ & NA & NA \\
\hline \multicolumn{6}{|c|}{ Hemoglobin, g/L } \\
\hline Placebo group & $134.7 \pm 15.1$ & $134.2 \pm 14.1$ & $135.8 \pm 11.0$ & $138.9 \pm 13.5$ & $138.2 \pm 15.9$ \\
\hline G-CSF group & $137.7 \pm 13.6$ & $136.2 \pm 15.0$ & $138.3 \pm 12.7$ & $139.0 \pm 13.0$ & $140.4 \pm 10.4$ \\
\hline \multicolumn{6}{|c|}{ Platelets, $\times 10^{9} / \mathrm{L}$} \\
\hline Placebo group & $253.9 \pm 78.7$ & $294.5 \pm 82.4$ & $334.7 \pm 100.3$ & $244.5 \pm 55.0$ & $242.8 \pm 60.2$ \\
\hline G-CSF group & $249.6 \pm 66.5$ & $304.4 \pm 59.8$ & $240.8 \pm 78.6 \dagger$ & $263.56 \pm 60.4$ & $253.7 \pm 36.2$ \\
\hline \multicolumn{6}{|c|}{ Leukocytes, $\times 10^{9} / \mathrm{L}$} \\
\hline Placebo group & $9.4 \pm 2.8$ & $9.2 \pm 2.7$ & $8.7 \pm 2.3$ & $7.5 \pm 2.0$ & $7.5 \pm 1.4$ \\
\hline G-CSF group & $9.6 \pm 2.3$ & $49.8 \pm 12.8 t$ & $9.1 \pm 3.3$ & $7.7 \pm 1.7$ & $8.1 \pm 2.3$ \\
\hline \multicolumn{6}{|c|}{ Lymphocytes, $\times 10^{9} / \mathrm{L}$} \\
\hline Placebo group & $2.0 \pm 0.6$ & $2.1 \pm 0.6$ & $1.9 \pm 0.5$ & $1.9 \pm 0.6$ & $2.0 \pm 0.6$ \\
\hline G-CSF group & $2.4 \pm 0.8$ & $5.0 \pm 2.6 \dagger$ & $2.2 \pm 0.7$ & $2.3 \pm 0.7$ & $2.5 \pm 0.8$ \\
\hline \multicolumn{6}{|c|}{ Monocytes, × 10\%/L } \\
\hline Placebo group & $0.6 \pm 0.2$ & $0.6 \pm 0.2$ & $0.6 \pm 0.3$ & $0.5 \pm 0.2$ & $0.4 \pm 0.1$ \\
\hline G-CSF group & $0.7 \pm 0.3$ & $2.5 \pm 1.5 t$ & $0.4 \pm 0.2$ & $0.5 \pm 0.1$ & $0.5 \pm 0.2$ \\
\hline \multicolumn{6}{|c|}{ Neutrophils, $\times 10^{9} / \mathrm{L}$} \\
\hline Placebo group & $6.5 \pm 2.3$ & $6.2 \pm 2.3$ & $6.0 \pm 2.0$ & $4.8 \pm 1.5$ & $4.5 \pm 1.2$ \\
\hline G-CSF group & $6.2 \pm 2.1$ & $37.7 \pm 10.0 \dagger$ & $5.7 \pm 2.2$ & $4.6 \pm 1.2$ & $4.7 \pm 1.7$ \\
\hline
\end{tabular}


placebo (relative risk $0.97,95 \%$ CI 0.73 to 1.30 , $p=0.9$; Appendix 2, Figure 3).

Notably, only 5 of the 14 clinical trials published to date have reported lower left ventricular ejection fraction with G-CSF therapy, the current study being the first with a statistically significant result. Although it may be tempting to dismiss our finding as an outlier, there are several potential explanations. First, the baseline ejection fraction in our study was about $35 \%$, considerably lower than in other reports. Indeed, the only other study involving patients with moderate left ventricular dysfunction reported that left ventricular ejection fraction was 3.0 percentage points lower with G-CSF. ${ }^{19}$ The only other large study with adequate power ${ }^{20}$ enrolled patients with nearnormal left ventricular ejection fraction and reported no difference in left ventricular recovery. Thus, it is possible that our trial is the first to detect possible harm, given the relatively mild degree of left ventricular dysfunction and the lack of power in previous studies. Notably, 3 other trials of G-CSF in patients with coronary artery disease were stopped early because of safety concerns: 1 trial for increased risk of in-stent restenosis ${ }^{8}$ and 2 trials for increased risk of acute coronary syndromes. ${ }^{10,11}$ This situation is particularly noteworthy given that research on G-CSF for patients with coronary disease or chronic left ventricular dysfunction (or both) is continuing.

Table 3: Characteristics of left ventricular ejection fraction and clinical outcomes

\begin{tabular}{|c|c|c|c|}
\hline \multirow[b]{2}{*}{ Variable or outcome } & \multicolumn{3}{|c|}{ Group; mean $(95 \% \mathrm{Cl})$ or no. $(\%)$ of patients } \\
\hline & $\begin{array}{c}\text { Placebo } \\
n=42\end{array}$ & $\begin{array}{l}\text { G-CSF } \\
n=42\end{array}$ & $p$ value \\
\hline \multicolumn{4}{|l|}{ Left ventricular ejection fraction, $\%$} \\
\hline Baseline & $36.4(33.5-39.2)$ & $34.8(32.6-37.0)$ & 0.4 \\
\hline 6 wk & $43.1(39.2-47.0)$ & $39.8(36.2-43.4)$ & 0.2 \\
\hline 26 wk & $46.0(42.7-44.3)$ & $40.8(37.4-44.2)$ & 0.04 \\
\hline Change, baseline to $26 \mathrm{wk}$, percentage points & $9.2(6.3-12.1)$ & $5.7 \quad(3.4-8.1)$ & 0.07 \\
\hline \multicolumn{4}{|l|}{ Outcome } \\
\hline Major adverse cardiac event & $8(19)$ & 8 (19) & $>0.9$ \\
\hline Death & $1 \quad(2)$ & $1 \quad(2)$ & $>0.9$ \\
\hline Coronary artery bypass graft & $1 \quad(2)$ & $1 \quad(2)$ & $>0.9$ \\
\hline Cardiac transplant & $0 \quad(0)$ & $1 \quad(2)$ & $>0.9$ \\
\hline Cerebrovascular accident & $0 \quad(0)$ & $1 \quad(2)$ & $>0.9$ \\
\hline Target-vessel revascularization & $6(14)$ & $5(12)$ & $>0.9$ \\
\hline Heart failure requiring admission & $3 \quad(7)$ & $1 \quad(2)$ & $>0.9$ \\
\hline
\end{tabular}

Table 4: Changes in diastolic function among patients who received placebo or G-CSF after myocardial infarction

\begin{tabular}{|c|c|c|c|c|c|c|c|c|c|}
\hline \multirow[b]{3}{*}{ Variable } & \multicolumn{9}{|c|}{ Time after treatment; group; mean $\pm S D^{*}$} \\
\hline & \multicolumn{3}{|c|}{ Baseline } & \multicolumn{3}{|c|}{$6 \mathrm{mo}$} & \multicolumn{3}{|c|}{ Change } \\
\hline & $\begin{array}{c}\text { Placebo } \\
n=42\end{array}$ & $\begin{array}{l}\text { G-CSF } \\
n=42\end{array}$ & $p$ value & $\begin{array}{c}\text { Placebo } \\
n=31\end{array}$ & $\begin{array}{l}\text { G-CSF } \\
n=34\end{array}$ & $p$ value & Placebo & G-CSF & $p$ value \\
\hline $\mathrm{e}^{\prime}$ lateral, $\mathrm{cm} / \mathrm{s}$ & $8.3 \pm 2.5$ & $8.8 \pm 1.4$ & 0.5 & $8.3 \pm 2.3$ & $9.7 \pm 2.4$ & 0.02 & $0.0 \pm 3.0$ & $-0.9 \pm 2.6$ & 0.2 \\
\hline Deceleration time, $\mathrm{s}$ & $0.17 \pm 0.04$ & $0.17 \pm 0.05$ & 0.4 & $0.21 \pm 0.05$ & $0.22 \pm 0.07$ & 0.6 & $-0.05 \pm 0.06$ & $-0.05 \pm 0.07$ & 0.7 \\
\hline E/A ratio & $1.2 \pm 0.5$ & $1.2 \pm 0.5$ & 0.4 & $1.2 \pm 0.8$ & $1.7 \pm 1.3$ & 0.2 & $-0.1 \pm 0.6$ & $-0.5 \pm 1.2$ & 0.3 \\
\hline E/e' ratio & $10.2 \pm 3.0$ & $8.8 \pm 2.2$ & 0.08 & $9.2 \pm 3.1$ & $7.7 \pm 3.5$ & 0.01 & $1.1 \pm 2.8$ & $1.2 \pm 3.3$ & 0.9 \\
\hline Left atrial volume, $\mathrm{mL}$ & $43.1 \pm 16.9$ & $46.3 \pm 14.8$ & 0.2 & $44.3 \pm 14.0$ & $57.4 \pm 23.5$ & 0.04 & $1.1 \pm 16.5$ & $11.1 \pm 23.2$ & 0.06 \\
\hline $\begin{array}{l}\text { Grade } 2 \text { or } 3, \text { no. (\%) } \\
\text { of patients }\end{array}$ & $9(29)$ & $12(35)$ & 0.8 & $5(16)$ & $12(35)$ & 0.1 & NA & NA & NA \\
\hline
\end{tabular}


A second possible explanation relates to the timing of G-CSF administration. In the current study, G-CSF therapy was not initiated until day 3 or 4 after infarction. Interestingly, positive data from animal studies used protocols with G-CSF administration before or at the time of infarct. ${ }^{21-24}$ By comparison, in a study of immediate versus delayed (5 d postinfarct) G-CSF therapy, delayed therapy was associated with a $24 \%$ increase in end diastolic volume and a significant increase in infarct mass relative to placebo. ${ }^{12}$ Similarly, a previous meta-analysis of clinical studies suggested benefit with early $(<37 \mathrm{~h})$ initiation of G-CSF therapy. ${ }^{5}$ Congruent with this hypothesis is the observation that the largest benefit reported to date in terms of left ventricular recovery occurred in a trial in which therapy was administered only 1.5 hours from the time of reperfusion. ${ }^{25}$ It is tempting to hypothesize that timing of G-CSF therapy is critical and that a lack of benefit may result from delayed initiation of therapy. Nonetheless, although methodologic and population differences may partly explain the difference, our study raises substantial concerns about the use of G-CSF in patients with moderate left ventricular dysfunction following myocardial infarction.

\section{Limitations}

This study had some limitations. We used a surrogate marker (final left ventricular ejection fraction) as our primary outcome. Although the study was not powered to detect differences in clinical events, follow-up left ventricular ejection fraction has been validated, both before and after PCI became available, as a powerful predictor of long-term mortality. ${ }^{26}$ As well, 4 patients in the G-CSF group and 2 patients in the placebo group did not undergo 26-week assessment of left ventricular ejection fraction, making postrandomization dropout a potential source of bias in this relatively small study. Interestingly, in the placebo group, left ventricular recovery was robust, at 9 percentage points over the 6-month follow-up period, more than double that predicted on the basis of previous studies. This observation is critical for future studies of novel therapies targeting left ventricular recovery, as larger sample sizes will ultimately be needed to demonstrate efficacy. Finally, the majority of patients recruited for this study were men, which limits the generalizability of our findings, given that important sex-specific differences in remodelling of the myocardium after myocardial infarction have been reported. ${ }^{27}$

\section{Conclusion}

Among patients with moderate left ventricular dysfunction after anterior wall infarction, delayed G-CSF therapy was associated with lower 6-month left ventricular ejection fraction but not with increased risk of major adverse cardiac events. Future studies of G-CSF therapy for patients with left ventricular dysfunction should be monitored closely for safety.

\section{References}

1. O'Gara PT, Kushner FG, Ascheim DD, et al. 2013 ACCF/AHA guideline for the management of ST-elevation myocardial infarction: a report of the American College of Cardiology Foundation/American Heart Association Task Force on Practice Guidelines. Circulation 2013;127:e362-425.

2. Assmus B, Honold J, Schachinger V, et al. Transcoronary transplantation of progenitor cells after myocardial infarction. $N$ Engl J Med 2006;355:1222-32.

3. Schächinger V, Erbs S, Elsasser A, et al. Intracoronary bone marrow-derived progenitor cells in acute myocardial infarction. N Engl J Med 2006;355:1210-21.

4. Crawford J, Ozer H, Stoller R, et al. Reduction by granulocyte colony-stimulating factor of fever and neutropenia induced by chemotherapy in patients with small-cell lung cancer. $N$ Engl J Med 1991;325:164-70.

5. Abdel-Latif A, Bolli R, Zuba-Surma EK, et al. Granulocyte colony-stimulating factor therapy for cardiac repair after acute myocardial infarction: a systematic review and meta-analysis of randomized controlled trials. Am Heart J 2008;156:216-26.

6. Zohlnhöfer D, Dibra A, Koppara T, et al. Stem cell mobilization by granulocyte colony-stimulating factor for myocardial recovery after acute myocardial infarction: a meta-analysis. J Am Coll Cardiol 2008;51:1429-37.

7. Shim W, Mehta A, Lim SY, et al. G-CSF for stem cell therapy in acute myocardial infarction: Friend or foe? Cardiovasc Res 2011;89:20-30.

8. Kang HJ, Kim HS, Zhang SY, et al. Effects of intracoronary infusion of peripheral blood stem-cells mobilised with granulocytecolony stimulating factor on left ventricular systolic function and restenosis after coronary stenting in myocardial infarction: the MAGIC cell randomised clinical trial. Lancet 2004;363:751-6.

9. Ma X, Hibbert B, White D et al. Contribution of recipientderived cells in allograft neointima formation and the response to stent implantation. PLoS One 2008;3:e1894

10. Zbinden S, Zbinden R, Meier P, et al. Safety and efficacy of subcutaneous-only granulocyte-macrophage colony-stimulating factor for collateral growth promotion in patients with coronary artery disease. J Am Coll Cardiol 2005;46:1636-42.

11. Hill JM, Syed MA, Arai AE, et al. Outcomes and risks of granulocyte colony-stimulating factor in patients with coronary artery disease. J Am Coll Cardiol 2005;46:1643-8.

12. Beohar N, Flaherty JD, Davidson CJ, et al. Granulocyte-colony stimulating factor administration after myocardial infarction in a porcine ischemia-reperfusion model: functional and pathological effects of dose timing. Catheter Cardiovasc Interv 2007;69:257-66.

13. Le May MR, Davies RF, Dionne R, et al. Comparison of early mortality of paramedic-diagnosed ST-segment elevation myocardial infarction with immediate transport to a designated primary percutaneous coronary intervention center to that of similar patients transported to the nearest hospital. Am J Cardiol 2006;98:1329-33.

14. Hibbert B, Macdougall A, Labinaz M, et al. Bivalirudin for primary percutaneous coronary interventions: outcome assessment in the Ottawa STEMI registry. Circ Cardiovasc Interv 2012;5:805-12.

15. Simard T, Hibbert B, Pourdjabbar A, et al. Percutaneous coronary intervention with or without on-site coronary artery bypass surgery: a systematic review and meta-analysis. Int J Cardiol 2013; 187:197-204.

16. Harada M, Qin Y, Takano H, et al. G-CSF prevents cardiac remodeling after myocardial infarction by activating the Jak-Stat pathway in cardiomyocytes. Nat Med 2005;11:305-11.

17. Kuhlmann MT, Kirchhof P, Klocke R, et al. G-CSF/SCF reduces inducible arrhythmias in the infarcted heart potentially via increased connexin 43 expression and arteriogenesis. $J$ Exp Med 2006;203:87-97

18. Anderlini P, Korbling M, Dale D, et al. Allogeneic blood stem cell transplantation: considerations for donors. Blood 1997;90:903-8

19. Ellis SG, Penn MS, Bolwell B, et al. Granulocyte colony stimulating factor in patients with large acute myocardial infarction: results of a pilot dose-escalation randomized trial. Am Heart $J$ 2006;152:1051 e9-14. 
20. Zohlnhöfer D, Ott I, Mehilli J, et al. Stem cell mobilization by granulocyte colony-stimulating factor in patients with acute myocardial infarction: a randomized controlled trial. JAMA 2006;295:1003-10.

21. Iwanaga K, Takano H, Ohtsuka M, et al. Effects of G-CSF on cardiac remodeling after acute myocardial infarction in swine. Biochem Biophys Res Commun 2004;325:1353-9.

22. Ohtsuka M, Takano H, Zou Y, et al. Cytokine therapy prevents left ventricular remodeling and dysfunction after myocardial infarction through neovascularization. FASEB J 2004; 18:851-3.

23. Sesti C, Hale SL, Lutzko C, et al. Granulocyte colony-stimulating factor and stem cell factor improve contractile reserve of the infarcted left ventricle independent of restoring muscle mass. $J$ Am Coll Cardiol 2005;46:1662-9.

24. Dawn B, Guo Y, Rezazadeh A, et al. Postinfarct cytokine therapy regenerates cardiac tissue and improves left ventricular function. Circ Res 2006;98:1098-105.

25. Ince H, Petzsch M, Kleine HD, et al. Preservation from left ventricular remodeling by front-integrated revascularization and stem cell liberation in evolving acute myocardial infarction by use of granulocyte-colony-stimulating factor (FIRSTLINEAMI). Circulation 2005;112:3097-106.

26. van der Vleuten PA, Rasoul S, Huurnink W, et al. The importance of left ventricular function for long-term outcome after primary percutaneous coronary intervention. BMC Cardiovasc Disord 2008;8:4.

27. Biondi-Zoccai GG, Abate A, Bussani R, et al. Reduced postinfarction myocardial apoptosis in women: A clue to their different clinical course? Heart 2005;91:99-101.

Affiliations: Division of Cardiology (Hibbert, Hayley, Beanlands, Le May, Davies, So, Marquis, Labinaz, Froeschl, O’Brien, Burwash, Wells, Pourdjabbar, Simard, Glover), Department of Medicine, University of Ottawa Heart Institute, Ottawa, Ont.; Libin Cardiovascular Institute (O’Brien), Calgary, Alta.; Division of Hematology (Atkins), Department of Medicine, The Ottawa Hospital and University of Ottawa, Ottawa, Ont.

Contributors: Benjamin Hibbert, Robert Beanlands, Richard Davies, Harold Atkins and Christopher Glover conceived and designed the study. Robert Beanlands, Michel Le May, Richard Davies, Derek So, Jean-François Marquis, Marino Labinaz, Michael Froeschl, Edward O'Brien, Ian Burwash and Harold Atkins collected the data. Benjamin Hibbert, Bradley Hayley, Robert Beanlands, Ian Burwash, George Wells, Ali Pourdjabbar, Trevor Simard, Harold Atkins and Christopher Glover analyzed and interpreted the data. George Wells performed the statistical analysis. Benjamin Hibbert, Bradley Hayley, Ali Pourdjabbar, Trevor Simard and Christopher Glover drafted the manuscript. Bradley Hayley, Robert Beanlands, Michel Le May, Richard Davies, Derek So, JeanFrançois Marquis, Marino Labinaz, Michael Froeschl, Edward O’Brien, Ian Burwash George Wells, Ali Pourdjabbar, Trevor Simard and Harold Atkins critically revised the manuscript for important intellectual content. All authors provided final approval for the version to be published, and all authors agree to be accountable for all aspects of the work in ensuring that questions related to the accuracy or integrity of any part of the work are appropriately investigated and resolved.

Funding: This clinical trial was supported by a grant-in-aid from the Canadian Institutes of Health Research (no. 74569) to Christopher Glover. Bradley Hayley was supported by a University of Ottawa Department of Medicine Fellowship Award. Robert Beanlands is a career investigator supported by the Heart and Stroke Foundation of Ontario and a Tier 1 Research Chair supported by the University of Ottawa. General Electric and the Canadian Foundation for Innovation provided an infrastructure grant to support the purchase of equipment. The funders had no role in study design, analysis of data or decision to publish the current study.

Acknowledgements: The authors are deeply indebted to Cathy Kelly and Ann Guo for their assistance in management of this trial. We would also like to thank Jordan Bernick for his assistance in performing the statistical analysis. Finally, we would like to thank Jane Sargent for her administrative support throughout the study. 